\title{
Profil Pasien Stroke di RSUD Arifin Achmad Provinsi Riau
}

\author{
Dimas Pramita Nugraha ${ }^{1}$, Eka Bebasari², Yulia Wardani ${ }^{3}$
}

\begin{abstract}
Stroke is the first cause of death in women and the second leading cause of death in men in industrialized countries. In Asia, every year an estimated 500 thousand people experience a stroke. Therefore recognizing stroke risk factors and managing them appropriately is key to designing primary prevention strategies in non-stroke populations and secondary prevention to avoid recurrent strokes. This research was cross sectional study to describe profile stroke patients in Arifin Achmad hospital Riau Province. Research data was taken through questionnaire and patient medical records. In this study, stroke patients in Arifin Achmad Hospital were mostly $<60$ years old, $65.80 \%$ and male sex $64.50 \%$. The proportion of hypertension is $90.80 \%$. Diabetes mellitus $7.90 \%$, dyslipidemia $63.20 \%$, smoking $21.10 \%$, obesity $32.90 \%$, and sedentary life $73.70 \%$.
\end{abstract}

Keywords: patients profile, stroke, hypertension

Penyakit serebrovaskular (stroke) merupakan penyebab kematian pertama pada wanita dan penyebab kematian kedua pada pria di negara industri. Stroke merupakan penyebab utama disabilitas. ${ }^{1,2}$ Faktor risiko merupakan kunci untuk merancang strategi pencegahan primer pada populasi non stroke dan pencegahan sekunder untuk menghindari stroke yang berulang. ${ }^{1,2}$

Asia khususnya di Indonesia, setiap tahun diperkirakan 500 ribu orang mengalami serangan stroke, dari jumlah itu sekitar 2,5 persen diantaranya meninggal dunia dan sisanya mengalami cacat ringan maupun cacat berat. Masyarakat Riau yang memiliki karakteristik penduduknya sebagian besar adalah Suku Melayu dengan demikian juga memiliki tantangan yang sama dalam mencegah terjadinya stroke dan meningkatkan angka harapan hidup.,4

Berbagai macam faktor risiko berhubungan dengan insidensi stroke diantaranya faktor risiko yang tidak dapat dimodifikasi seperti usia, jenis kelamin, berat badan lahir rendah, genetik, serta ras/etnik.

\footnotetext{
* Penulis untuk korespondensi :dr_dimas_nugraha@ yahoo.com

KJF Farmakologi FK UNRI

KJF Fisiologi FK UNRI

3 KJF Ilmu Penyakit Mata FK UNRI
}

Faktor risiko yang dapat dimodifikasi diantaranya adalah hipertensi, diabetes melitus, penyakit jantung, obesitas, dislipidemia, merokok, serta perilaku sedentari, stres dan masih banyak lagi faktor risiko kejadian stroke. ${ }^{3,4}$

\section{METODE}

Penelitian ini merupakan penelitian cross sectional dengan menggunakan kuisioner dan rekam medik di RSUD Arifin Achmad Provinsi Riau. Populasi pada penelitian ini adalah pasien rawat jalan yang didiagnosis menderita stroke sebanyak 397 orang. Penentuan besar sampel penelitian ini menggunakan rumus Slovin, dan didapatkan jumlah sampel sebesar 76 orang. Variabel penelitian adalah hipertensi, diabetes mellitus, dislipidemia, perilaku sedentari, merokok, dan obesitas. Data tentang hipertensi, diabetes mellitus, dislipidemia dan obesitas diambil dari reklam medik. Data merokok diambil dari wawancara dan perilaku sedentari di nilai dari kuisioner sedentary behaviour quisioner (SBQ).

\section{HASIL}

Hasil penelitian menunjukkan ada kecenderungan kejadian stroke meningkat pada 
pasien dengan kelompok usia $<60$ tahun $(65,80 \%)$, dan stroke lebih banyak dijumpai pada kelompok pria $(64,50 \%)$ dibandingkan wanita (35,50\%) (Gambar 1 dan 2)

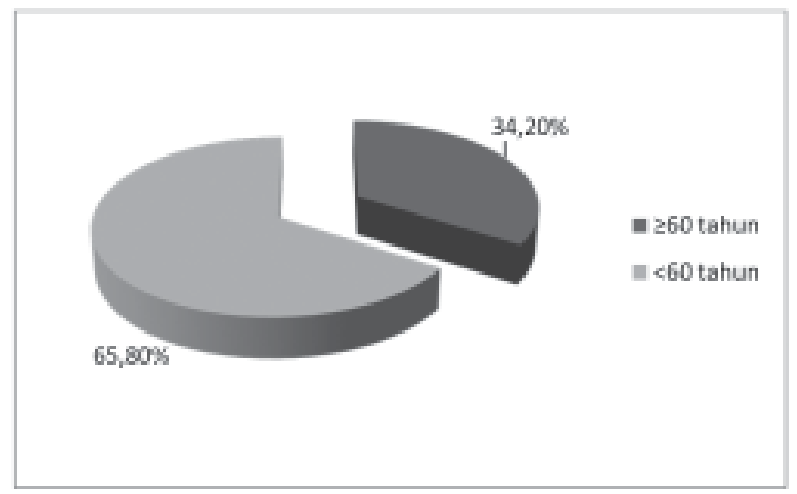

Gambar 1. Karakteristik Usia Pasien Stroke

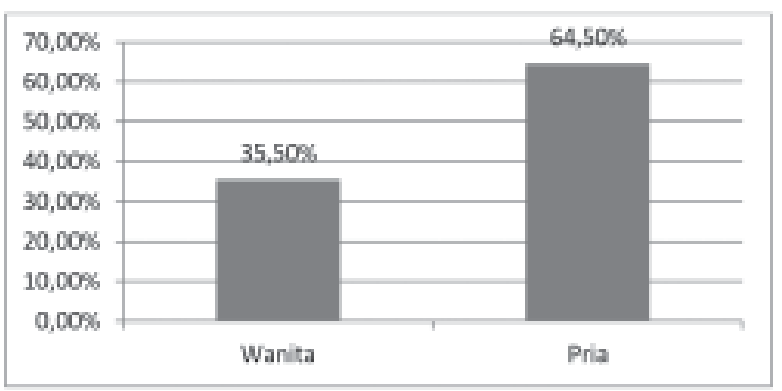

Gambar 2. Karakteristik Usia Jenis Kelamin Pasien Stroke

Indeks massa tubuh (IMT) pasien proporsinya sebagian besar diatas indeks berat badan normal, dengan kelompok pasien dengan overweight memiliki persentase terbesar (35,50\%), obesitas grade 1 (23,70\%) dan obesitas grade 2 (9,20\%) seperti yang di tunjukkan oleh gambar 3.

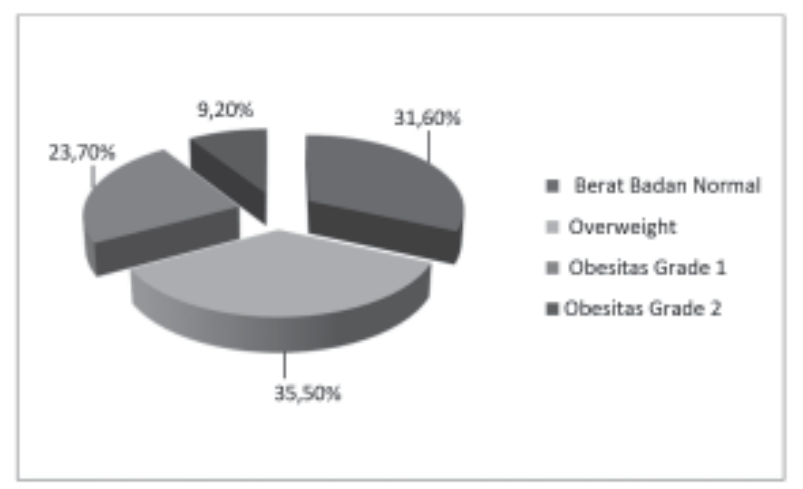

Gambar 3. Indeks Massa Tubuh Pasien Stroke
Sebagian besar pasien stroke pada penelitian ini menderita hipertensi (90,8\%) (gambar 4).

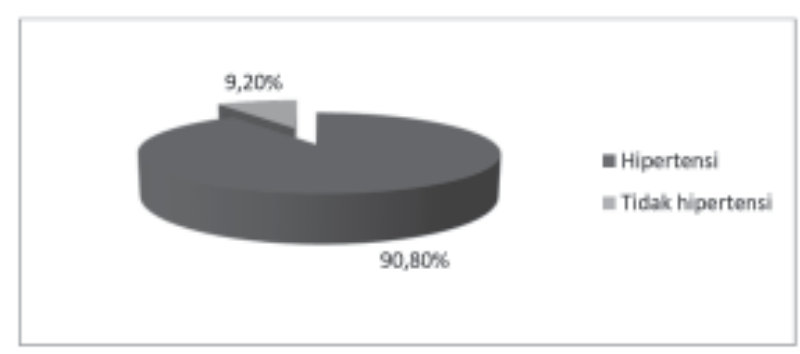

Gambar 4. Hipertensi Pada Pasien Stroke

Pada penelitian ini juga dijumpai pasien stroke dengan dislipidemia sebesar 63,20\% dibandingkan yang tidak memiliki dislipidemia 36,80\% (gambar 5).

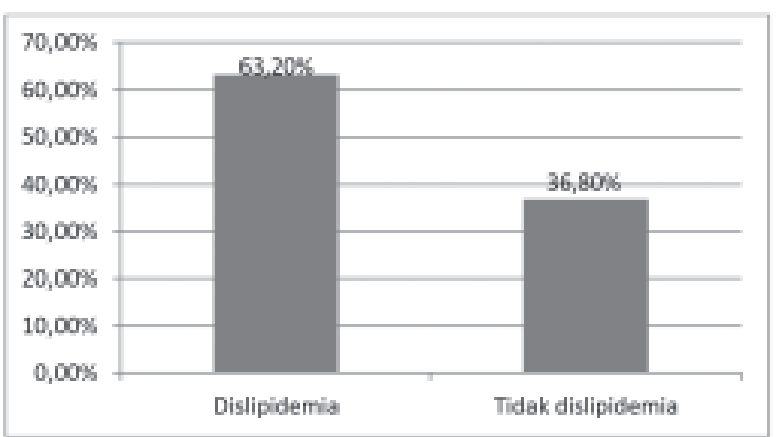

Gambar 5. Dislipidemia Pada Pasien Stroke

Sebagian kecil pasien stroke pada penelitian ini menderita diabetes mellitus yaitu 7,90\% seperti yang ditunjukkan pada gambar 6 .

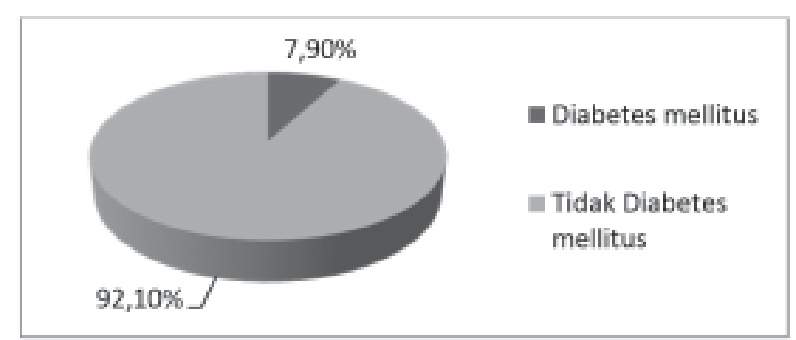

Gambar 6. Diabetes Pada Pasien Stroke

Hasil penelitian menunjukkan hanya 21,10\% pasien yang memiliki riwayat merokok, sebagian besar tidak merokok (78,9\%) (gambar 7). 


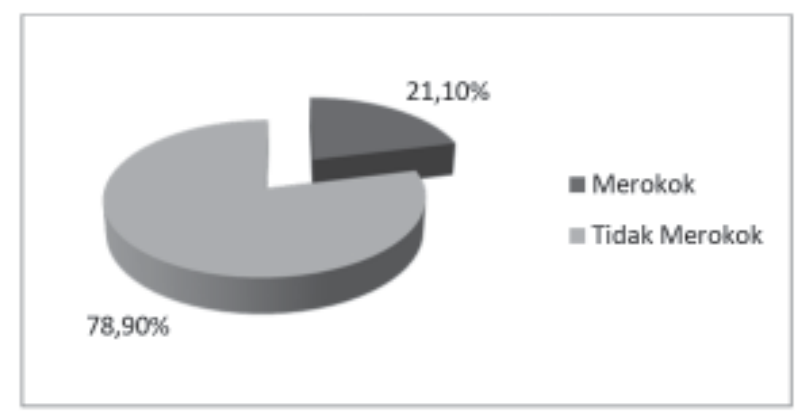

Gambar 7. Riwayat Merokok pada pasien stroke

Gambar 8 menunjukkan bahwa sebagian besar pasien stroke pada penelitian ini memiliki perilaku hidup sedentary (73,70\%).

Gambar 8. Perilaku Hidup Sedentari Pada Pasien Stroke

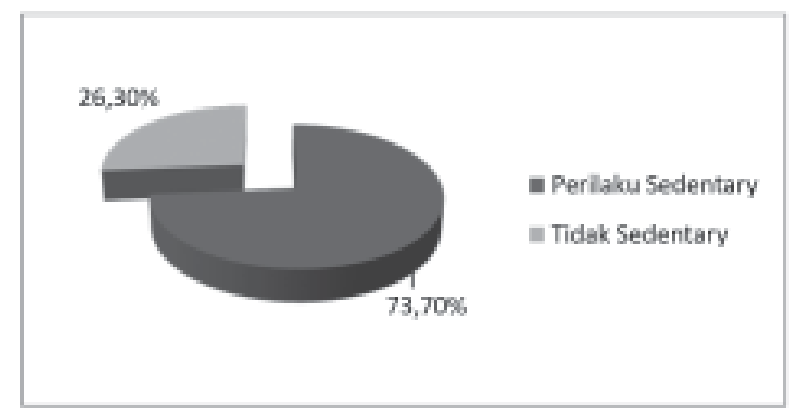

\section{PEMBAHASAN}

\section{Karakteristik Usia}

Semakin bertambahnya usia maka elastisitas pembuluh darah semakin berkurang. Namun, pada penelitian ini tampak bahwa ada kecenderungan kejadian stroke meningkat pada kelompok pasien usia $<60$ tahun $(65,80 \%)$ dibandingkan pasien kelompok usia $>60$ tahun. Hasil ini menunjukkan bahwa ada pergeseran angka kejadian stroke ke usia yang lebih muda, kondisi ini dapat disebabkan berbagai faktor, diantaranya perilaku hidup sedentari dan pola makan yang tidak sehat. Hasil ini berbeda dengan apa yang didapatkan oleh Arboix di Spanyol tahun 2015 dimana dijumpai proporsi angka kejadian stroke sebagian besar pada usia $>65$ tahun keatas. Insiden stroke meningkat dua kali lipat setiap dekade pada usia diatas 55 tahun. ${ }^{1,10}$

\section{Karakteristik Jenis Kelamin}

Penelitian ini menunjukkan bahwa pasien stroke sedikit lebih banyak dijumpai pada kelompok pria (64,50\%) dibandingkan wanita (35,50\%). Proporsi ini berbeda dengan apa yang dikemukakan oleh Boehme et al (2017), bahwa hubungan jenis kelamin dengan risiko stroke terkait dengan usia. Pada usia muda, wanita memiliki risiko stroke yang sama atau bahkan lebih tinggi dari pria, tetapi pada usia yang lebih tua pria memiliki risiko relatif terjadinya stroke yang lebih tinggi. Tingginya risiko stroke pada wanita di usia muda berkaitan dengan kehamilan, kondisi pasca melahirkan dan faktor hormonal salah satunya penggunaan kontrasepsi hormonal. Studi yang dilakukan di delapan negara eropa yang berbeda menunjukkan bahwa risiko stroke meningkat 9\% pertahun pada pria dan $10 \%$ pertahun pada wanita. 10

\section{Faktor Risiko Hipertensi}

Sebagian besar pasien stroke pada penelitian ini menderita hipertensi $(90,80 \%)$. Hipertensi meningkatkan 4 kali risiko terjadinya stroke, dan risiko terjadinya perdarahan cerebral 3,9 kali dibandingkan orang tanpa hipertensi. Hipertensi merupakan faktor risiko yang dapat di modifikasi yang paling penting, dimana terdapat hubungan yang kuat, linier, langsung dan berkelanjutan antara tekanan darah dengan risiko terjadinya stroke. ${ }^{1,3,10}$

Sebuah metaanalisis dari 147 studi melibatkan 464.000 orang yang tanpa memiliki riwayat penyakit vaskular dan stroke, menunjukkan bahwa menurunkan tekanan darah sistolik $10 \mathrm{mmHg}$ atau diastolik $5 \mathrm{mHg}$ berkaitan dengan penurunan 40 persen risiko terjadinya stroke. ${ }^{10,11}$

\section{Faktor Risiko Dislipidemia}

Pada penelitian ini jumlah pasien yang menderita dislipidemia sebesar 63,20\%. Plasma lipid dan lipoprotein (kolesterol total, HDL, LDL, trigliserida) meningkatkan risiko terjadinya infark cerebral. Studi epidemiologi faktor risiko stroke pada 350.000 orang di Eropa menunjukkan hubungan yang kuat antara peningkatan kadar kolesterol dengan angka kematian akibat stroke. ${ }^{1,11}$ 


\section{Faktor Risiko Diabetes mellitus}

Hasil penelitian menunjukkan bahwa tidak banyak pasien stroke dalam penelitian ini yang menderita diabetes mellitus (7,90\%). Namun faktor risiko diabetes tetap harus menjadi perhatian. Diabetes mellitus merupakan faktor risiko independen untuk kejadian stroke iskemik. Kombinasi hiperkolesterolemia dan hipertensi akan meningkatkan kejadian komplikasi vaskular pada pasien dengan diabetes mellitus. Risiko relatif stroke pada pasien orang yang menderita diabetes mellitus berkisar 1,8 sampai dengan 6 , dan penderita diabetes cenderung menderita stroke di usia yang lebih muda. ${ }^{10,11}$

\section{Faktor Risiko Merokok}

Sebanyak 21,10\% pasien memiliki riwayat merokok. Merokok merupakan prediktor independen penyakit serebrovaskular pada pria maupun wanita. Perokok memiliki risiko relatif 1,92 kali untuk kejadian stroke iskemik jika dibandingkan orang yang tidak merokok. Merokok meningkatkan risiko pembentukan trombus pada pembuluh arteri kecil dan berkontribusi untuk terbentuknya plak aterosklerosis. Merokok juga meningkatkan viskositas darah, fibrinogen dan agregasi trombosit, dan menurunkan kolesterol HDL yang dapat menyebabkan kerusakan langsung pada endotel serta meningkatkan tekanan darah. ${ }^{1,10,11}$

\section{Faktor Risiko Obesitas}

Hasil penelitian menunjukkan bahwa proporsi pasien stroke dengan obesitas (obesitas grade 1+ obesitas grade 2 ) sebesar $32,90 \%$, dan bila ditambahkan lagi dengan kelompok overweight maka akan didapatkan proporsi IMT yang diatas normal sebesar $68,40 \%$. Hasil ini bertolak belakang dengan yang didapatkan oleh Sukmawati L di Rumah Sakit Kariadi Semarang pada tahun 2012 dimana proporsi pasien stroke dengan obesitas hanya 1,3\%. Perbedaan ini dimungkinkan karena adanya perbedaan pola diet masyarakat. Masyarakat Sumatera khususnya Riau sangat dekat dengan makanan yang tinggi lemak dan mengandung santan. Mengurangi berat badan dan obesitas sentral dapat menurunkan tekanan darah dan tentunya mengurangi risiko terjadinya stroke. ${ }^{1,2}$

\section{Faktor Risiko Perilaku hidup Sedentari}

Perilaku hidup sedentari pada pasien stroke pada penelitian ini relatif besar (73,70\%). Kondisi ini menunjukkan bahwa perilaku atau gaya hidup masyarakat sudah mulai bergeser ke arah sedentari atau kurang melakukan pergerakan. Aktivitas fisik yang teratur sangat baik untuk menurunkan risiko penyakit kardiovaskular dan stroke. Data metaanalisis dari 23 studi menunjukkan bahwa orang yang memiliki aktivitas fisik yang tinggi memiliki risiko stroke yang lebih rendah dibandingkan orang yang memiliki aktivitas fisik rendah (risiko relatif: $0,87) .^{1,9,10,11}$

Berbagai faktor risiko stroke yang diamati dalam penelitian ini, hipertensi merupakan faktor risiko yang memiliki proporsi yang paling besar yaitu 90,80\%. Proporsi ini mungkin dapat berbeda di berbagai tempat yang berbeda, sebagai contoh di Amerika Serikat prevalensi hipertensi sebagi faktor risiko yang dapat dimodifikasi sebesar $30 \%$. Kondisi ini dipengaruhi oleh berbagai faktor seperti genetik, perbedaan etnik, diet, perilaku sedentari, stress dan sebagainya. ${ }^{9,10,11}$

Sebagian besar pasien memiliki tidak hanya satu faktor risiko saja, tetapi lebih dari satu faktor risiko, misalnya hipertensi dengan obesitas, diabetes dengan merokok atau lebih dari dua faktor misalnya hipertensi + perilaku sedentari + dislipidemia. Pasien yang memiliki faktor risiko yang banyak tentunya cenderung memiliki risiko kejadian stroke yang lebih besar. ${ }^{11}$

Perubahan gaya hidup dan menghindari faktor risiko stroke yang dapat dimodifikasi merupakan pendekatan yang perlu dilakukan untuk mencegah terjadinya stroke serta menurunkan morbiditas dan mortalitas akibat stroke. ${ }^{10,11}$

\section{KESIMPULAN}

Pada Penelitian ini pasien stroke di RSUD Arifin Achmad sebagian besar berusia $<60$ tahun 65,80\% dan berjenis kelamin pria 64,50\%. Proporsi hipertensi 90,80\%. Diabetes mellitus 7,90\%, dislipidemia $63,20 \%$, merokok $21,10 \%$, obesitas $32,90 \%$, dan perilaku hidup sedentari $73,70 \%$. Faktor risiko stroke yang memiliki proporsi paling besar di RSUD Arifin Achmad adalah hipertensi. 


\section{UCAPAN TERIMA KASIH}

Ucapan terimakasih disampaikan kepada Lembaga Penelitian dan Pengabdian Kepada Masyarakat Universitas Riau yang telah mendanai penelitian ini.

\section{DAFTAR PUSTAKA}

1. Arboix A. Cardiovascular risk factors for acute stroke: Risk profiles in the different subtypes of ischemic stroke. World J Clin Case.s 2015; 3(5): 418-29

2. Sukmawati L, Jenie MN, Anggraheny HM. Analisis faktor risiko stroke di Rumah Sakit Umum Pusat Dr.Kariadi Semarang. 2012.

3. Wibowo S dan Gofir A, Farmakoterapi dalam neurologi. Salemba Medika. Jakarta. 2001.

4. Ropper, AH and Brown, RH., Adam \& victor's : Principles of neurology, Ed $8^{\text {th }}$ McGrow-Hill.
5. Howland RD and Mycek MJ. Lippincott's lllustrated Reviews: Phamacology, Thid Edition. Lippincot Williams\& WilkinsB, Baltimore.2006.

6. Taylor RB. A Handbook Cardiovascular Disease. Springer Sciences. New York. 2005.

7. Finkel. Ilustrated Pharmacology. Lipincott. 2008.

8. Irdelia RR, Joko AT, dan Bebasari E. Profil faktor risiko yang dapat dimodifikasi pada kasus stroke berulang di RSUD Arifin Achmad Provinsi Riau. JOM FK UNRI 2014. 1(2).

9. Bray GA and Bouchard C. Handbook of obesity. 2nd ed. Marcel Dekkel Inc. New York. 2005.

10. Boehme AK, Esenwa C, and Elkind MSV. Stroke risk factors, genetics, and prevention. Circ Res.2017.120(3): 472-95.

11. Romero JR, Morris J, and Pikula A. Stroke prevention: modifying risk factors. Ther Adv Cardiovasc Dis. 2008 August ; 2(4): 287-303. 